\section{Influence of incubation} conditions on biofilm formation by Pseudomonas fluorescens isolated from dairy products and dairy manufacturing plants

\author{
Chiara Rossi,' Clemencia Chaves-López,' \\ Annalisa Serio, ${ }^{1}$ Elisa Goffredo, ${ }^{2}$ \\ Beniamino Terzo Cenci Goga, ${ }^{3}$ \\ Antonello Paparella'
}

${ }^{1}$ Faculty of Bioscience and Technology for Food, Agriculture and Environment, University of Teramo, Mosciano S. Angelo (TE); ${ }^{2}$ Veterinary Public Health Institute of Apulia and Basilicata, Foggia; ${ }^{3}$ Department of Veterinary Medicine, University of Perugia, Perugia, Italy

\section{Abstract}

In this study, biofilm formation of 64 Pseudomonas fluorescens strains isolated from milk, dairy products and dairy plants was compared. The strains were grown on Tryptic Soy Broth supplemented with $0.2 \%$ of glucose, on polystyrene microplates at 10 and $30^{\circ} \mathrm{C}$ for $48 \mathrm{~h}$. In general, 57/64 P. fluorescens strains formed biofilm, although with great variability at both tested temperatures. Moreover, our results evidenced that the biofilm-forming ability of the strains was temperature- and strain-dependent. Interestingly, the ability of several isolates to form biofilms was associated with the low temperature after $48 \mathrm{~h}$. Our findings evidenced that temperature was more important than incubation time for biofilm formation. Considering the origin of the strains, it is relevant to underline the importance of performing accurate cleaning and disinfection procedures on food processing surfaces.

\section{Introduction}

The genus Pseudomonas is a heterogeneous group of microorganisms, belonging to the Pseudomonadaceae family, which includes ubiquitous Gram negative, aerobic, non-fermentative, catalase and oxidase positive, mesophilic and psychrotolerant, nonspore forming rods (Caldera et al., 2016). Pseudomonas members are adapted to a wide range of conditions and can be found in many different environments such as soil, water, plants, animal tissues, and foods (Franzetti and Scarpellini, 2007). In addition, they possess iron-uptake systems based on syderophores and therefore can make iron unavailable for other microorganisms (Caixeta et al., 2012).

Pseudomonas species can produce different pigments such as pyoverdin, pyocyanin (Carrascosa et al., 2015), and indigoidine (Caputo et al., 2015). In particular, P. fluorescens induces changes in structure and colour of food products, due to production of lecithinase (phospholipase C), proteolytic enzymes, and pigmented molecules. Moreover, pigment-producing Pseudomonas grows rapidly at low temperatures and produces exopolysaccharides, which contribute to biofilm formation (Caixeta et al., 2012).

In food environments, biofilms become reservoirs of pigment-producing Pseudomonas, and can enhance their resistance to several environmental stresses that are commonly encountered in food processing (e.g. refrigeration, acidity, salinity, disinfection) (Giaouris et al., 2014; Wang and Jayarao, 2001). Furthermore, biofilms are extremely difficult to remove and control, and therefore cause enormous problems with possible production and plant shutdowns that cost millions in lost revenue (Cloete et al., 2009).

Some species of the Pseudomonas genus can grow during refrigerated storage of raw milk in both farms and dairy plants (De Jonghe et al., 2011) and are considered important milk spoilage organisms. In fact, they produce many thermotolerant lipolytic and proteolytic enzymes that affect the quality and shelf life of processed milk (Dogan and Boor, 2003). By the same token, due to the their ability to form biofilms, they can also contaminate previously processed milk (Kives et al., 2006). In addition, biofilm detachment during processing can contribute to the contamination of the finished product (Cleto et al., 2012), and post-processing contamination can cause cheese spoilage and shelf life reduction (Segat et al., 2014). In fact, some authors reported that Pseudomonas grown on the cheese surface mostly derives from water (Cantoni et al., 2003; Leriche et al., 2004) but also from food contact surfaces and piping of the processing lines (Sharma and Anand, 2002). Dairy products can be considered important sources of strains with different physiological characteristics that might behave differently with regard to biofilm formation.

Thus, given the great interest in the genus Pseudomonas in the dairy industry, the aim of this study was to characterise the Pseudomonas fluorescens strains on the basis of the capability to form biofilm on polystyrene surface and the influence of the temperature and time incubation on biofilm formation.
Correspondence: Antonello Paparella, Faculty of Bioscience and Technology for Food, Agriculture and Environment, University of Teramo, via C.R. Lerici 1, 64023 Mosciano S. Angelo (TE), Italy. Tel:/Fax: +39.0861.266944.

E-mail: apaparella@unite.it

Key words: Biofilm; Pseudomonas fluorescens; Dairy products; Mozzarella cheese.

Conflict of interest: the authors declare no potential conflict of interest.

Received for publication: 2 February 2016.

Revision received: 16 March 2016.

Accepted for publication: 19 May 2016.

This work is licensed under a Creative Commons Attribution-NonCommercial 4.0 International License (CC BY-NC 4.0).

(C) Copyright C. Rossi, et al., 2016

Licensee PAGEPress, Italy

Italian Journal of Food Safety 2016; 5:5793

doi:10.4081/ijfs.2016.5793

\section{Materials and Methods}

\section{Microbial strains and growth condi- tions}

The bacteria used in this study were 64 Pseudomonas fluorescens strains isolated from milk, dairy products and dairy plants. The strains were maintained at $-80^{\circ} \mathrm{C}$ in cryovials, containing an anti-freezing agent (glycerol, 20\% v/v; Sigma Aldrich, St. Louis, MO, USA) to preserve the viability of the cells during storage. The origin of the strains is reported in Table 1. Before the evaluation of the biofilm formation, bacterial strains were grown overnight in Tryptic Soy Broth (TSB; Oxoid, Basingstoke, UK), at $30^{\circ} \mathrm{C}$ under aerobic conditions. After $24 \mathrm{~h}$ of incubation, 1 $\mathrm{mL}$ of bacterial suspension was inoculated into fresh TSB supplemented with $0.2 \%$ of glucose, and incubated at $30^{\circ} \mathrm{C}$ for $18 \mathrm{~h}$ to obtain a working fresh culture. Bacteria were harvested by centrifugation at $13,000 \mathrm{~g}$ (Eppendorf Centrifuge 5415D; Eppendorf, Hamburg, Germany) for $5 \mathrm{~min}$ at $4^{\circ} \mathrm{C}$ and washed for three times with Phosphate Buffer Saline (PBS) $50 \mathrm{mM} \mathrm{pH} \mathrm{7.0,} \mathrm{according}$ to Mazzarrino et al. (2015). Inocula were standardised at about $5 \times 10^{5}$ cells $/ \mathrm{mL}$, by means of absorbance measures at $590 \mathrm{~nm}$ (Lambda Bio 20; Perkin Elmer, Waltham, MA, USA). Inocula were confirmed by plate counts on Pseudomonas Agar Base supplemented with Pseudomonas CFC supplement (PSA; Oxoid), incubated at $30^{\circ} \mathrm{C}$ for $24 \mathrm{~h}$. 


\section{Biofilm formation}

Biofilm-forming ability of $P$. fluorescens was measured in 96-well polystyrene microplates. Each strain was tested in 5 replicates after inoculation of a standardised culture in TSB added with $0.2 \%$ of glucose. Negative control wells contained non-inoculated TSB with glucose. Samples $(200 \mu \mathrm{L})$ were dispensed into wells, and the microplates were incubated at 10 and $30^{\circ} \mathrm{C}$ for 24 and $48 \mathrm{~h}$.

\section{Biofilm assay}

The planktonic cells were removed from each well, and the plates were rinsed three times with deionised water. Excess moisture was removed by tapping the microplates on sterile napkins, and the plates were dried for $15 \mathrm{~min}$. Then, biofilm formation was quantified by crystal violet assay, as reported by Sabaeifard et al. (2014), with some modifications. In detail, the wells were stained with $200 \mu \mathrm{L}$ of $0.1 \%$ crystal violet (Sigma-Aldrich) solution at room temperature for $30 \mathrm{~min}$, and then the microplates were washed with deionised water to remove the stain. After drying, crystal violet was solubilised in $250 \mu \mathrm{L}$ of $30 \%$ acetic acid glacial (Carlo Erba Reagenti SpA, Milan, Italy).

Five absorbance values obtained for each strain were used to calculate means and standard deviations, by subtracting the value of control from each mean value.

The absorbance at $590 \mathrm{~nm}$ [optical density $\left.(\mathrm{OD})_{590}\right]$ was measured, and the strains were grouped into: $0 \mathrm{D}_{590}<0.1$, non-producers (NP); $\mathrm{OD}_{590}=0.1-1.0$, weak producers (WP); $\mathrm{OD}_{590}=1.1-3.0$, moderate producers (MP); and $\mathrm{OD}_{590}>3.0$, strong producers (SP).

\section{Statistical analysis}

Means and standard deviations were calculated for the five replicates of $\mathrm{OD}_{590}$ measures and the means were compared by Student's t-test, fixing $\mathrm{P}<0.05$.

\section{Results}

In the microplates used to evaluate biofilm-forming ability, a greater biofilm formation was observable by the naked eye after staining at the interface between the air and the liquid medium (at the upper limit of the
$200 \mu \mathrm{L}$ ), probably because of oxygen availability. The comparison of the biofilm-forming capability of individual strains, classified on the basis of OD, is shown in Figure 1. The standard deviation of values obtained for each individual strain was lower than $1 \%$. In general, a great variability in biofilm-forming ability, in terms of OD values, was observed

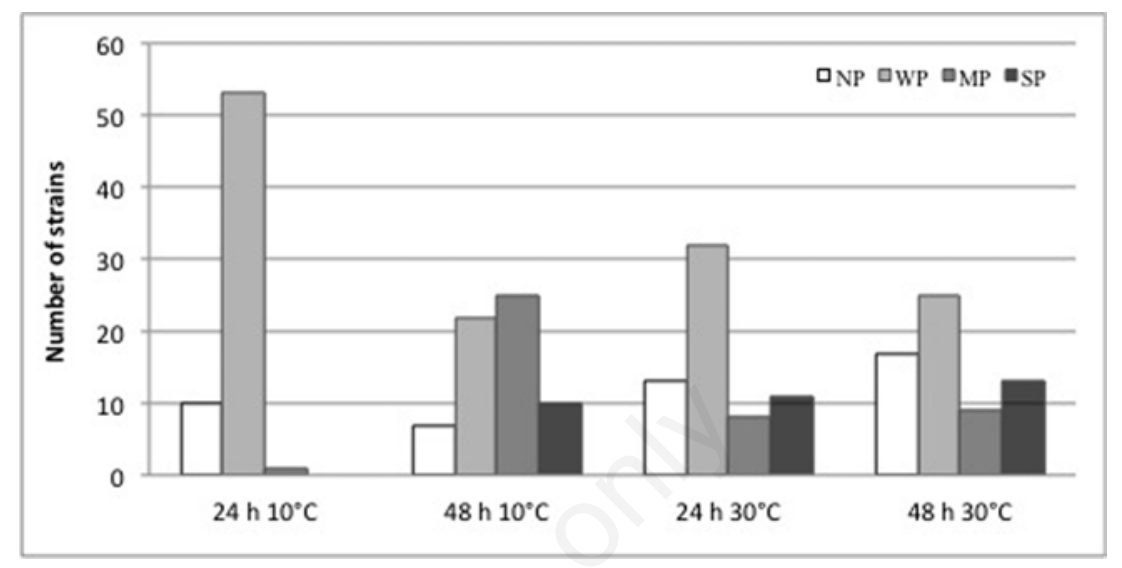

Figure 1. Biofilm formed by the 64 Pseudomonas fluorescens strains at different incubation times and temperatures. White, non-producers (NP); light grey, weak producers (WP); dark grey, moderate producers (MP); black, strong producers (SP).

Table 1. Number of Pseudomonas fluorescens strains and their origins.

\begin{tabular}{lc} 
Origins & P. fluorescens strains (n) \\
Mozzarella cheese & 46 \\
Milk & 5 \\
\hline Scamorza & 4 \\
Brine & 3 \\
\hline Cheese & 1 \\
Curd & 1 \\
\hline Butter & 1 \\
Burrata & 1 \\
\hline Mozzarella manufacturing plant & 1 \\
Ice machine & 1 \\
\hline
\end{tabular}

P. fluorescens, Pseudomonas fluorescens.

Table 2. Number of Pseudomonas fluorescens strains capable of producing biofilm after $48 \mathrm{~h}$ of incubation.

\begin{tabular}{|c|c|c|c|c|c|c|c|c|c|}
\hline \multirow[t]{2}{*}{ Origins } & \multirow[t]{2}{*}{ Total strains (n) } & \multicolumn{4}{|c|}{$10^{\circ} \mathrm{C}$} & \multicolumn{4}{|c|}{$30^{\circ} \mathrm{C}$} \\
\hline & & NP & WP & MP & SP & NP & WP & MP & SP \\
\hline Mozzarella cheese & 46 & 4 & 17 & 15 & 10 & 12 & 18 & 3 & 13 \\
\hline Milk & 5 & 0 & 4 & 1 & 0 & 2 & 1 & 2 & 0 \\
\hline Scamorza & 4 & 0 & 0 & 4 & 0 & 1 & 1 & 2 & 0 \\
\hline Brine & 3 & 1 & 0 & 2 & 0 & 1 & 1 & 1 & 0 \\
\hline Cheese & 1 & 1 & 0 & 0 & 0 & 0 & 0 & 1 & 0 \\
\hline Curd & 1 & 0 & 1 & 0 & 0 & 0 & 1 & 0 & 0 \\
\hline Butter & 1 & 0 & 0 & 1 & 0 & 0 & 1 & 0 & 0 \\
\hline Burrata & 1 & 1 & 0 & 0 & 0 & 0 & 1 & 0 & 0 \\
\hline Mozzarella manufacturing plant & 1 & 0 & 0 & 1 & 0 & 1 & 0 & 0 & 0 \\
\hline Ice machine & 1 & 0 & 0 & 1 & 0 & 0 & 1 & 0 & 0 \\
\hline
\end{tabular}

NP, non-producers; WP, weak producers; MP, moderate producers; SP, strong producers. 
among the different Pseudomonas fluorescens strains.

Although low temperature $\left(10^{\circ} \mathrm{C}\right)$ contributed significantly to the biofilm formation more than high temperature $\left(30^{\circ} \mathrm{C}\right)$, the latter promoted a stronger biofilm formation without significant differences $(\mathrm{P}>0.05)$ depending on incubation time. On the contrary, significant differences $(\mathrm{P}<0.05)$ were observed in the numbers of biofilm producers and in their total biofilm biomass (expressed as $\mathrm{OD}_{590}$ ) at $10^{\circ} \mathrm{C}$. In particular, during the first $24 \mathrm{~h}, 54 / 64$ strains produced biofilm at $10^{\circ} \mathrm{C}$ and $51 / 64$ at $30^{\circ} \mathrm{C}$, whereas after $48 \mathrm{~h}$ the number of biofilm-producer strains increased up to $57 / 64$ at $10^{\circ} \mathrm{C}$ but decreased to 47 strains at $30^{\circ} \mathrm{C}$. As regards the level of biofilm formation, after $24 \mathrm{~h}$ no strain formed a strong biofilm at $10^{\circ} \mathrm{C}$, while eleven strains produced a strong biofilm at $30^{\circ} \mathrm{C}$; however, after $48 \mathrm{~h}$ the number of the strong biofilm producers increased at both incubation temperatures. Thus, it seems that during the first $24 \mathrm{~h}$, temperature was more important than incubation time, for adhesion of $P$. fluorescens to the surface.

Table 2 shows the number of $P$. fluorescens strains that were able to form biofilm after 48 $\mathrm{h}$ of incubation, listed according to strain of origin. In this study, although it was not possible to correlate the origin of the strains with their ability to produce biofilm, a strong biofilm-forming capacity was observed in several strains isolated from mozzarella cheese samples, with 10 and 13 SP strains at 10 and $30^{\circ} \mathrm{C}$, respectively.

\section{Discussion}

The ability to adhere to solid surfaces and the consecutive formation of an organised bacterial biofilm community are important steps in the establishment of Pseudomonas spp. in dairy manufacturing plants. In addition, it is well known that the switch from planktonic to a biofilm mode of growth is an intricate process, which occurs in response to changes in environmental conditions (O'Toole et al., 2000).

In this study, we observed that the majority of strains of $P$. fluorescens isolated from dairy products and dairy manufacturing plants was able to form biofilm in microtiter plate wells, with variations related to the biodiversity of strains. As the first step of biofilm formation is bacterial adhesion to surfaces, we can hypothesise that the strains showed a good ability to create hydrophobic interactions with polystyrene surfaces. However, Lemos et al. (2014) suggested that surface physical and chemical properties are not the main factor regulating the initial adhesion process

\section{for $P$. fluorescens.}

In this work, we observed that biofilm formation in $P$. fluorescens strains was promoted at $10^{\circ} \mathrm{C}$ : generally strains not able to produce biofilm at $30^{\circ} \mathrm{C}$ were instead weak or particularly moderate producers at $10^{\circ} \mathrm{C}$. It is accepted that biofilm formation is enhanced by cell motility, particularly when it is mediated by flagella, and under certain environmental conditions flagella are necessary for biofilm formation in P. fluorescens (Robleto et al., 2003). Thus, we can hypothesise that the biofilm-forming ability of the strains here studied could be due to bacterial surface appendages that can be temperature-dependent as in L. monocytogenes. In this respect, integration of many diverse signals from the environment might play a role in biofilm formation, together with other events such as phenotypic and genetic switching during biofilm production and release of extracellular polymeric substances (Simões et al., 2010).

On the other hand, the rapid decrease of biofilm-forming capacity that we observed at $30^{\circ} \mathrm{C}$ after $48 \mathrm{~h}$ of incubation could be attributed to the loss of exopolymers from the biofilm and in particular of exopolysaccharides, which may suggest that an active process of detachment was occurring, probably mediated by enzymatic degradation (Allison et al., 1998).

\section{Conclusions}

In conclusion, we observed that the biofilm-forming ability of $P$. fluorescens strains was temperature- and strain-dependent. In general, lower incubation temperatures $\left(+10^{\circ} \mathrm{C}\right)$ favoured the formation of biofilm after $48 \mathrm{~h}$, probably because the strains were well adapted to the low temperatures applied both in production environment and in storage conditions. Further studies are necessary to assay the adhesive strength of $P$. fluorescens on other materials such as stainless steel, in order to highlight the conditions that affect the biofilm-forming ability of $P$. fluorescens in the dairy industry.

\section{References}

Allison DG, Ruiz B, SanJose C, Jaspe A, Gilbert P, 1998. Extracellular products as mediators of the formation and detachment of Pseudomonas fuorescences biofilms. FEMS Microbiol Lett 167:17984.

Caixeta DS, Scarpa TH, Brugnera DF, Freire D0, Alves E, Abreu LR, Piccoli RH, 2012.
Chemical sanitizers to control biofilms formed by two Pseudomonas species on stainless steel surface. Cien Tecnol Alim 32:142-50.

Caldera L, Franzetti L, Van Coillie E, De Vos P, Stragier P, De Block J, Heyndrickx M, 2016. Identification, enzymatic spoilage characterization and proteolytic activity quantification of Pseudomonas spp. isolated from different foods. Food Microbiol 54:142-53.

Cantoni C, Stella S, Cozzi M, Iacumin L, Comi G, 2003. Colorazione blu di mozzarelle. Ind Aliment 42:840-3.

Caputo L, Quintieri L, Bianchi DM, Decastelli L, Monaci L, Visconti A, Baruzzi F, 2015. Pepsin-digested bovine lactoferrin prevents Mozzarella cheese blue discoloration caused by Pseudomonas fluorescens. Food Microbiol 46:15-24.

Carrascosa C, Millán R, Jaber JR, Lupiola P, del Rosario-Quintana C, Mauricio C, Sanjuán E, 2015. Blue pigment in fresh cheese produced by Pseudomonas fluorescens. Food Control 54:95-102.

Cleto S, Matos S, Kluskens L, Vieira MJ, 2012. Characterization of contaminants from a sanitized milk processing plant. PLoS ONE 7:e40189.

Cloete E, Molobela I, Van Der Merwe A, Richards M, 2009. Biofilms in the food and beverage industries: an introduction. In: Fratamico PM, Annous BA, Gunther NW, eds. Biofilms in the food and beverage industries. Elsevier, New York, NY, USA, pp. 3-41.

De Jonghe V, Coorevits A, Van Hoorde K, Messens W, Van Landschoot A, De Vos P, Heyndrickx M, 2011. Influence of storage conditions on the growth of Pseudomonas species in refrigerated raw milk. Appl Environ Microb 77:460-70.

Dogan B, Boor KJ, 2003. Genetic diversity and spoilage potentials among Pseudomonas spp. isolated from fluid milk products and dairy processing plants. Appl Environ Microb 69:130-8.

Franzetti L, Scarpellini M, 2007. Characterisation of Pseudomonas spp. isolated from foods. Ann Microbiol 57:3947.

Giaouris E, Heir E, Hébraud M, Chorianopoulos N, Langsrud S, Møretrø T, Habimana 0, Desvaux M, Renier S, Nychas GJ, 2014. Attachment and biofilm formation by foodborne bacteria in meat processing environments: causes, implications, role of bacterial interactions and control by alternative novel methods. Meat Sci 97:289-309.

Kives J, Orgaz B, Sanjosé C, 2006. Polysaccharide differences between planktonic and biofilm-associated EPS from Pseudomonas fluorescens B52. 
Colloid Surface 52:123-7.

Lemos M, Borges A, Teodósio J, Araújo P, Mergulhão F, Melo L, Simões M, 2014. The effects of ferulic and salicylic acids on Bacillus cereus and Pseudomonas fluorescens single- and dual-species biofilms. Int Biodeter Biodegr 86:42-51.

Leriche F, Bordessoules A, Fayolle K, Karoui R, Laval K, Leblanc L, Dufour E, 2004. Alteration of raw-milk cheese by Pseudomonas spp.: monitoring the sources of contamination using fluorescence spectroscopy and metabolic profiling. J Microbiol Meth 59:33-41.

Mazzarrino G, Paparella A, Chaves-López C, Faberi A, Sergi M, Sigismondi C, Compagnone D, Serio A, 2015. Salmonella enterica and Listeria mono- cytogenes inactivation dynamics after treatment with selected essential oils. Food Control 50:794-803.

0’Toole G, Kaplan HB, Kolter R, 2000. Biofilm formation as microbial development. Annu Rev Microbiol 54:49-79.

Robleto EA, López-Hernández I, Silby MW, Levy SB, 2003. Genetic analysis of the AdnA regulon in Pseudomonas fluorescens: non essential role of flagella in adhesion to sand and biofilm formation. J Bacteriol 185:453-60.

Sabaeifard P, Abdi-Ali A, Soudi MR, Dinarvand R, 2014. Optimization of tetrazolium salt assay for Pseudomonas aeruginosa biofilm using microtiter plate method. J Microbiol Meth 105:13440.
Segat A, Biasutti M, Iacumin L, Comi G, Baruzzi F, Carboni C, Innocente N, 2014. Use of ozone in production chain of high moisture Mozzarella cheese. LWT-Food Sci Technol 55:513-20.

Sharma M, Anand SK, 2002. Characterization of constitutive microflora of biofilms in dairy processing lines. Food Microbiol 19:627-36.

Simões LC, Simões M, Vieira MJ, 2010. Adhesion and biofilm formation on polystyrene by drinking water-isolated bacteria. Anton Leeuw Int J G 98:317-29.

Wang L, Jayarao BM, 2001. Phenotypic and genotypic characterization of Pseudomonas fluorescens isolated from bulk tank milk. J Dairy Sci 84:1421-9. 